\title{
Initial Experience on Anatomical Snuff Box Approach for Coronary Angiogram \& Percutaneous Coronary Intervention in a Tertiary Care Center Nepal
}

\author{
Ratna Mani Gajurel*, Ravi Sahi, Hemant Shrestha, Sanjeev Thapa, Rajaram Khanal \\ Department of Cardiology, Manmohan Cardio Vascular Thoracic and Transplant Centre (MCVTC), Institute of Medicine, \\ TUTH, Maharajgunj, Nepal \\ Email: *ratnamanigajurel@gmail.com
}

How to cite this paper: Gajurel, R.M., Sahi, R., Shrestha, H., Thapa, S. and Khanal, R. (2018) Initial Experience on Anatomical Snuff Box Approach for Coronary Angiogram \& Percutaneous Coronary Intervention in a Tertiary Care Center Nepal. World Journal of Cardiovascular Diseases, 8, 578-587. https://doi.org/10.4236/wjcd.2018.812057

Received: November 12, 2018

Accepted: December 25, 2018

Published: December 28, 2018

Copyright $\odot 2018$ by authors and Scientific Research Publishing Inc. This work is licensed under the Creative Commons Attribution International License (CC BY 4.0).

http://creativecommons.org/licenses/by/4.0/

cC) (i) Open Access

\begin{abstract}
Introduction: Coronary Angiogram and Percutaneous Coronary Interventions are commonly performed via the femoral route. Then, transradial coronary catheterization became a popular \& default technique due to less vascular access site complications and bleeding as compared to femoral route. Distal puncture of the radial artery through the anatomical snuff box access, however, has recently been shown potential benefit, like comfort to patients and operators, as well as maintenance of blood flow through the superficial palmar arch, in case of radial artery occlusion. Our aim was to evaluate the safety and feasibility of this new approach. Methods: A cross-sectional observational prospective study of patients underwent invasive diagnostic or therapeutic coronary procedures through the distal trans-radial access and traditional radial access. The primary endpoints were to access difficulties and in-hospital access-site related complications. Results: In 2 months, 190 patients underwent coronary procedures, of which $82(43 \%)$ were selected in both distal transradial \& traditional radial group. In 2 (2.4\%) \& 3 (3.6\%) cases, distal radial \& traditional radial access cannulation was unsuccessful respectively $(\mathrm{p}>0.05)$. The mean age was $57.7 \pm 10 \& 57.2 \pm 10$ years in successful distal transradial $\&$ traditional radial cases respectively. There were no any major vascular complications in distal transradial group while there were 2 vascular complications in traditional radial group ( $p>0.05$ ). Conclusions: Distal transradial access is feasible and safe in selected cases, when performed by experienced operators. Larger case series and randomized trials are required to determine its efficacy in reducing vascular complications when comparing to the traditional technique.
\end{abstract}




\section{Keywords}

CAD: Coronary Artery Disease, CAG: Coronary Angiogram,

PCI: Percutaneous Coronary Intervention, Radial Artery: RA

\section{Introduction}

Coronary intervention has continuously progressed since the first procedure done in 1929 [1] by Werner Frossman. Coronary Angiogram (CAG) \& Percutaneous Coronary Intervention (PCI) are important interventions to diagnose and treat for atherosclerosis Coronary Artery Disease (CAD). It can be performed via transradial, transbrachial or transfemoral access. PCI through femoral artery was first successfully done in 1977 and only 12 years later in 1989, Campeau [2] first reported a series of 100 diagnostic CAGs by radial approach. In early 1990, Kiemeneij \& Laarman [3] performed balloon angioplasty and PCI through radial artery.

Transradial approach is the current choice and also default technique for both diagnostic \& therapeutic invasive coronary procedures, with prognostic impact on patients' morbidity and mortality, especially for those who are at hemorrhagic complications [4].

Distal radial artery access from the anatomical snuff box (AS) was described for the first time by Babunashvili et al. [5] in order to open occluded ipsilateral radial arteries in a retrograde fashion. It was then introduced for coronary catheterization as a new technique by Dr F Kiemeneij [6] in April 2017 and in same year in December, Dr Shigeru Saito performed Kamakura live demonstration. The anatomical snuffbox is triangular deepening on the radial side of the wrist visible on extended thumb; it is bounded posteriorly by the tendon of the extensor pollicis longus and anteriorly by the tendons of the extensor pollicis brevis and abductor pollicis longus. Specifically, the scaphoid and the trapezium bones form the floor crossed by the radial artery (RA) [7] (Figure 1).

In the past, this hollow space was used to hold ground tobacco before inhaling via the nose. Hence, it was given the name "snuff box" [8] (Figure 2).

It has been recently introduced as a refinement of the technique described 25 years ago [9]. Its advantage over traditional radial access is offering greater comfort to patient as well as operator during the procedure. Besides, it also maintains antegrade blood through the superficial palmar arch (Figure 3) in case of radial artery occlusion. The other benefits are the reduction in the incidence of complications related to the site of puncture, short hospital stay [10] and preserve the radial artery for revascularization procedure, like coronary artery bypass graft or creating AV-fistulas in CKD patients. The mean diameter of RA at the snuff box of $2.5 \mathrm{~mm}$ (range $1.5-4.1 \mathrm{~mm}$ ) by using ultrasound, suggests this size may be a problem for only a minority of patients during transradial access [11]. 


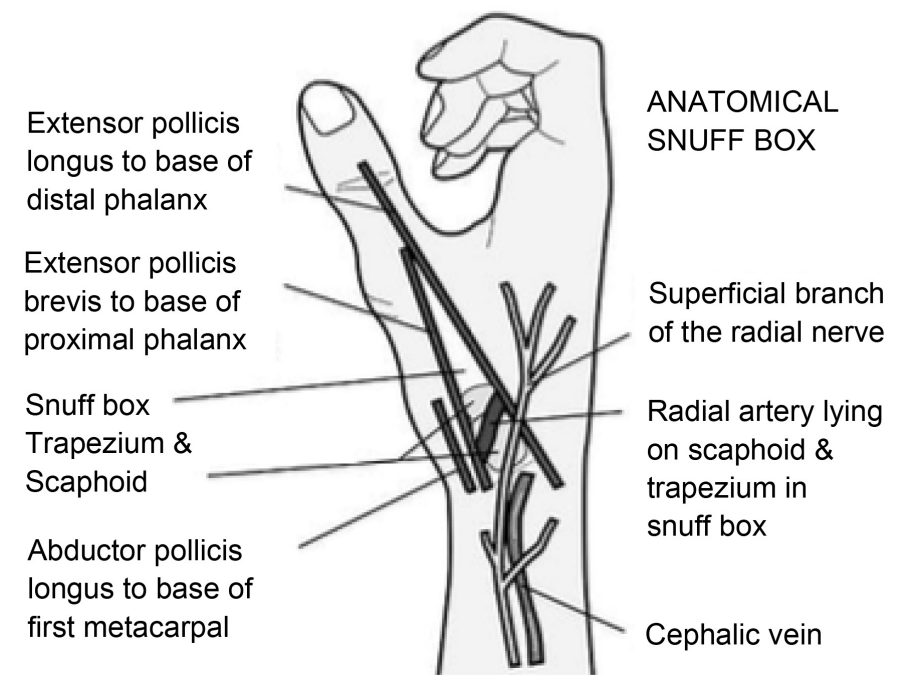

Figure 1. The anatomical snuffbox references.

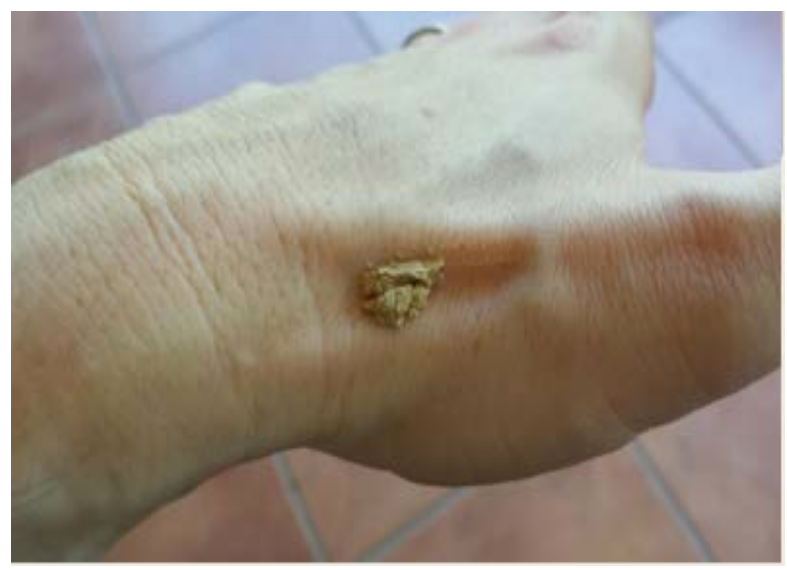

Figure 2. Anatomical Snuff box holding ground tobacco.

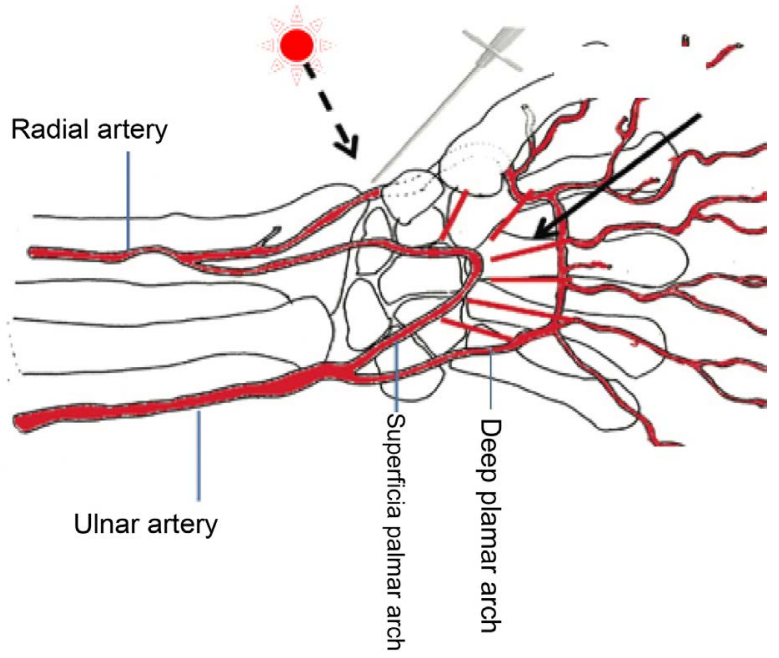

Figure 3. Puncture needle in the anatomical snuffbox (dotted arrow). Straight black arrow depicting the collaterals between the superficial and deep palmar arch. 
With this prospective observational study, we aimed to analyze the feasibility and safety of performing cardiac interventions through the distal transradial access, without any additional equipment or cost.

\section{Methods}

A cross sectional observational prospective study of patients who underwent invasive diagnostic or therapeutic coronary procedures through the distal trans radial artery and traditional radial artery approach in Department of Cardiology, Manmohan Cardio Vascular Thoracic and Transplant Centre (MCVTC), Institute of Medicine, TUTH, Nepal, from July 2018 to August 2018.

First, all patients underwent an Allen test, when normal color did not return to the hand less than 10 seconds after removing pressure on the cubital artery was considered abnormal [12]. The patient were placed in a decubitus supine position by curling the thumb with other four fingers and making AS more prominent on the hand support system in the semi prone position close to the body. The operator performed on right side of patients preparing for right distal trans radial artery (DTRA) or traditional right radial (TRA) artery puncture. Under local anesthetic (lignocaine 2\%), we performed the puncture with a 21 -gauge needle with a $30^{\circ}-45^{\circ}$ angle medial to laterally and then introduced a straight 0.018 -inch guide wire with a soft, flexible proximal part and rigid distal part, followed by the introduction of a $5 / 6 \mathrm{~F}$ for radial hydrophilic sheath according to procedure for distal radial access into the radial artery (Figure 4(a) and Figure 4(b)). All patients received 2500 units of sodium heparin (additional

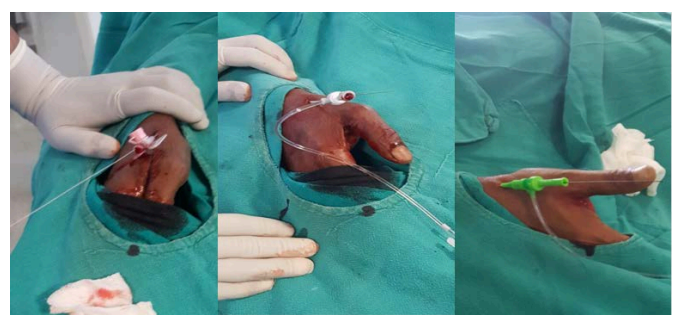

(a)

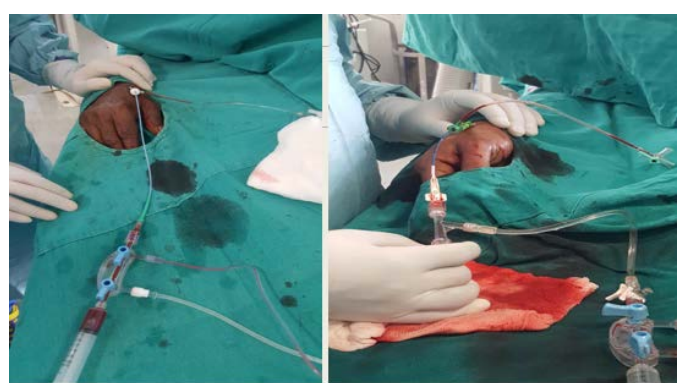

(b)

Figure 4. (a) The introduction of 5/6 French hydrophilic radial sheath into the right distal trans radial artery in the anatomical snuffbox. (b) Operator on the right side of the patient performing coronary interventions with right DTRA. 
heparin was administered up to a total of 7500 units for PCI) in conjunction with $2.5 \mathrm{mg}$ verapamil and $200 \mu \mathrm{g}$ nitroglycerine to prevent arterial spasm, through the lateral catheter before the procedure was begun. The introductory catheter was guided up to the ascending aorta, and then the angiographic catheters were inserted. The choice of catheters was left to the specialist according to need of the patients and procedure where Tiger, JL,JR or XB were most frequently used. The introductory catheter was removed immediately in all patients after completion of procedure and hemostasis was achieved by means of an elastic compressor bandage, without using compression devices [13] (Figure 5). The bandage was kept in place for at least 3 - 4 hours. The patient was allowed to ambulate immediately after the procedure.

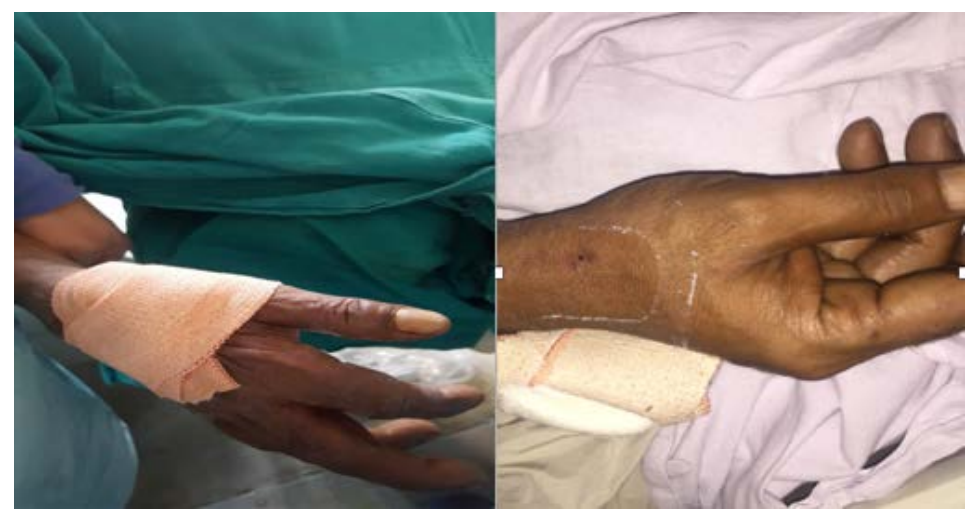

Figure 5. Hemostasis obtained by compressive dressing with semi-elastic adhesive bandage and gauze.

We gathered the data from each patient including total time for the procedure, fluoroscopy time, incidence of puncture difficulties \& complications. All patients were evaluated 4 - 6 hours. After the procedure and while removing the elastic bandage at the puncture point, we noted the absence or presence of palpable hematomas, pain on palpation of the puncture area, and the presence of a distal radial pulse. In the absence of a radial pulse, distal radial artery obstruction was considered present to the puncture site or an abnormal inverse Allen test result [14].

The following were inclusion \& exclusion criteria:

\section{Inclusion Criteria:}

1) All patients who underwent CAG \& PCI

2) All patients with good amplitude pulse at snuff box area.

3) Vascular access site: distal trans radial access (anatomical snuff box).

\section{Exclusion Criteria}

1) Patient who don't have good amplitude of pulse at snuff box area.

2) All primary PCI cases.

3) Previous cases that had underwent CAG \& PCI.

\section{Statistical Analysis}

SPSS software, version 20.0 was used to analyze all statistical data. Categorical 
data were analyzed in terms of frequency and continuous data presented as means \pm SD. Dichotomous variables were compared by Chi-square test and independent samples $t$ test used to compare means of continuous variables. The $p$ value $<0.05$ was considered to be statistically significant.

\section{Results}

Out of 190 patients who underwent coronary procedures, of which 82 (43\%) were selected in both distal trans radial $\&$ traditional radial group. The mean age was $57.7 \pm 10 \& 57.2 \pm 10$ years in successful distal transradial \& traditional radial cases respectively.

Demographic data and risk factors of the two groups (Table 1).

Table 1. Clinical, Angiographic and procedure characteristics.

\begin{tabular}{|c|c|c|c|}
\hline & $\begin{array}{c}\text { Distal Tans } \\
\text { Radial }(\mathrm{n}=82)\end{array}$ & $\begin{array}{c}\text { Traditional radial } \\
\qquad(\mathrm{n}=82)\end{array}$ & $\mathrm{p}$ value \\
\hline Variables & $\mathrm{n} \%$ & $\mathrm{n} \%$ & \\
\hline Mean age, years & $57.7 \pm 10$ & $57.2 \pm 10$ & \\
\hline Male & $48(58.5)$ & $44(53.6)$ & 0.529 \\
\hline Hypertension & $29(35.3)$ & $24(29.2)$ & 0.404 \\
\hline Smoking & $36(43.9)$ & $27(32.9)$ & 0.148 \\
\hline Diabetes & $21(25.6)$ & $15(18.2)$ & 0.258 \\
\hline Dyslipidemia & $17(20.7)$ & $10(12.1)$ & 0.140 \\
\hline BMI $(<25)$ & $57(69.5)$ & $58(70.7)$ & 0.865 \\
\hline $\mathrm{BMI}(\geq 25)$ & $25(30.4)$ & $24(29.2)$ & \\
\hline Successful puncture & $80(97.6)$ & $79(96.4)$ & \\
\hline Failure (Arterial spasm) & $2(2.4)$ & $3(3.6)$ & 0.650 \\
\hline Introducer Sheath diameter & & & 0.548 \\
\hline 5-French & $26(31.7)$ & $20(24.3)$ & \\
\hline 6-French & $54(65.8)$ & $59(71.9)$ & \\
\hline Type of procedure & & & 0.103 \\
\hline CAG & $60(73.1)$ & $47(57.3)$ & \\
\hline PCI & $20(24.3)$ & $32(39)$ & \\
\hline Severity of CAD & & & 0.540 \\
\hline Normal Coronaries & $30(36.5)$ & $35(42.6)$ & \\
\hline Minor Coronary artery disease & $10(12.1)$ & $4(4.8)$ & \\
\hline Single vessel disease & $16(19.5)$ & $18(21.9)$ & \\
\hline Double vessel disease & $8(9.7)$ & $10(12.1)$ & \\
\hline Triple vessel disease & $16(19.5)$ & $12(14.6)$ & \\
\hline Left main disease & 0 & 0 & \\
\hline Artery puncture time (min) & & $1.2 \pm 0.94$ & \\
\hline Fluoroscopy time (min) & & $9.6 \pm 7.1(1.2-40.1)$ & \\
\hline
\end{tabular}

BMI: Body mass index, CAG: Coronary angiogram, PCI: Percutaneous coronary intervention, CAD: Coronary artery disease. 
No significant differences in demographic data including gender and age were found between the two groups $(\mathrm{P}>0.05)$. There were no significant differences in diabetes, hypertension, or dyslipidemia between the two groups $(\mathrm{P}>0.05)$.

In total we had $60 \& 47$ diagnostic and $20 \& 32$ therapeutic procedures in distal trans radial \& traditional radial access respectively, in both group $6 \mathrm{~F}$ radial sheath were most used. In DTRA 30 (36.5\%) while in TRA 35 (42.6\%) had normal coronaries and none of them had left main disease. Both DTRA \& TRA access was successful in $80(97.6 \%) \& 79(96.4 \%)$ patients respectively. Two patients (2.4\%) \& three patients (3.6\%) from each group distal trans radial and traditional radial access were shifted into transfemoral access due to arterial spasm. In both access the mean time to puncture of artery was $1.2 \mathrm{~min}$ and mean fluoroscopy time was $9.6 \mathrm{~min}$.

Postoperative complications in the two groups (Table 2).

The distal trans radial artery group had no cases of postoperative complication while in traditional radial approach 2 of cases had hematoma which was no significant difference in the two groups $(\mathrm{P}>0.05$, Table 2$)$.

\section{Discussion}

Our outcomes confirmed that DTRA was as safe and effective as TRA, with the benefits of shorter hospital stay and lower complication rates. This approach has been practiced for several years in the world [5] [6] [15] and has become popular in our country in recent years. However, technical difficulties and long learning curve limit the use of DTRA by many interventional cardiologists.

To avoid the possible discomfort that may arise from prolonged procedure, the start of vascular access of TRA right hand was kept along the side of the body with fingers and wrist kept in dorsi flexed state with a support in supine position (Figure 6) but during DTRA patient's hand was kept in semi prone position

Table 2. Postoperative complications in the two groups.

\begin{tabular}{cccc}
\hline & $\begin{array}{c}\text { Distal Tans Radial } \\
(\mathrm{n}=82)\end{array}$ & $\begin{array}{c}\text { Traditional radial } \\
(\mathrm{n}=82)\end{array}$ & P value \\
\hline Variables & $\mathrm{n} \%$ & $\mathrm{n} \%$ & \\
Hematoma & $0(0)$ & $2(2.4)$ & 0.155 \\
\hline
\end{tabular}

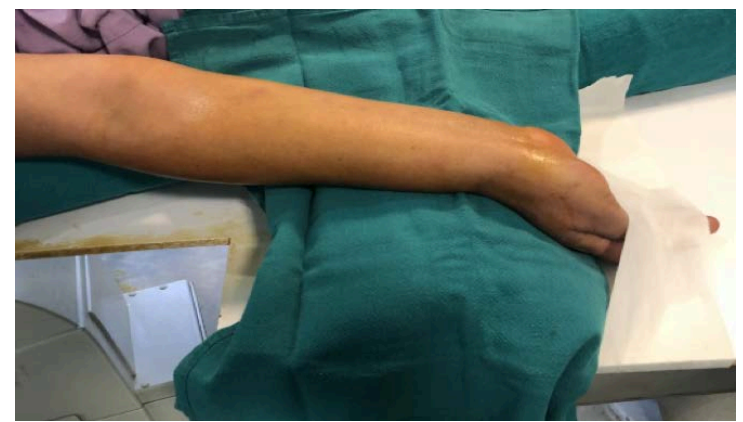

Figure 6. The wrist in extension with the aid of a towel roll during TRA. 
without any support. Patients suffering from shoulder injuries or other orthopedic problems may have supination of their arms difficulty, benefit from the DTRA.

More importantly, it benefits in patients whose radial site has been recently used. Potential site for retrograde recanalization of radial artery occlusion; arterial entry is beyond compartments of forearm reducing risk of compartment syndrome.

As most of the operators are used to do right sided puncture, so majority of right TRA and right DTRA was chosen in our study.

In total, the visual analog scale score was low (2). Although it is not an objective scale, it showed that the patients were comfortable during the procedure in DTRA in comparison to TRA.

Regarding the possibility of hand ischemia Kaledin et al. [12] shows that DTRA access is a safer choice compared to TRA in addition to the preservation of the palmer arch during DTRA is responsible for this advantage over TRA. Their study showed out of 2589 cases that underwent coronary intervention very less had complications like hematoma (0.2\%). Our study also supports their findings where $2.4 \%$ patients undergoing TRA developed hematoma.

Several studies involving TRA showed that the most common complication during the trans radial coronary angiography is post-catheterization radial artery occlusion reported in $1 \%-10 \%$ patients undergoing catheterization [16] but we encounter none from both DTRA \& TRA. As a result, it influenced us to utilize the DTRA as the access site as relatively high rates of this complication are seen in TRA.

In the study of Kiemeniej F [6] and Elton Soydan et al. [17], out of 70 and 54 patients respectively who underwent coronary intervention through distal trans radial access none of them had complications like hematoma, numbness which was very much similar to our study.

In order to prevent radial artery occlusion, radial artery spasm, and extended procedure times, this new radial approach should be kept in mind.

\section{Limitation of the Study}

The present study had some limitations that need to be considered. This was a study in a single center with small sample size. In minority of patients, DTRA could be challenging due to smaller diameter of RA in comparison with TRA and also its access requires a steeper learning curve.

\section{Conclusion}

Use of distal transradial artery in the current era of interventional cardiology opens another alternate route to heart and coronary arteries. Although the procedural success, advantages and complication rates appear to be similar to those for the traditional transradial approach, this approach also leads to preservation of the radial artery which can be used as a conduct in subsequent revasculariza- 
tion procedures.

Thus, DTRA is a safe and convenient alternative approach for performing routine cardiac catheterizations.

\section{Conflicts of Interest}

The authors declare no conflicts of interest regarding the publication of this paper.

\section{References}

[1] Mueller, R.L. and Sanborn, T.A. (1995) The History of Interventional Cardiology; Cardiac Catheterization, Angioplasty and Related Interventions. American Heart Journal, 129, 146-172. https://doi.org/10.1016/0002-8703(95)90055-1

[2] Campeau, L. (1989) Percutaneous Radial Artery Approach for Coronary Angiography. Catheterization and Cardiovascular Diagnosis, 16, 3-7. https://doi.org/10.1002/ccd.1810160103

[3] Kiemeneij, F. and Laarman, G.J. (1994) Percutaneous Transradial Artery Approach for Coronary Palmaz-Schatz Stent Implantation. American Heart Journal, 128, 167-174. https://doi.org/10.1016/0002-8703(94)90023-X

[4] Sandoval, Y., Burke, M.N., Lobo, A.S., Lips, D.L., Seto, A.H., Chavez, I., et al. (2017) Contemporary Arterial Access in the Cardiac Catheterization Laboratory. JACC: Cardiovascular Interventions, 10, 2233-2241. https://doi.org/10.1016/j.jcin.2017.08.058

[5] Babunashvili, A. and Dundua, D. (2011) Recanalization and Re-Use of Early Occluded Radial Artery within 6 Days after Previous Transradial Diagnostic Procedure. Catheterization and Cardiovascular Interventions, 77, 530-536. https://doi.org/10.1002/ccd.22846

[6] Kiemeneij, F. (2017) Left Distal Transradial Access in the Anatomical Snuffbox for Coronary Angiography (IdTRA) and Interventions (IdTRI). EuroIntervention, 13, 851-857. https://doi.org/10.4244/EIJ-D-17-00079

[7] Cerda, A. and del Sol, M. (2015) Anatomical Snuffbox and it Clinical Significance: A Literature Review. International Journal of Morphology, 33, 1355-1360. https://doi.org/10.4067/S0717-95022015000400027

[8] Oliverjones. https://teachmeanatomy.info/upper-limb/areas/anatomical-snuffbox/

[9] Kiemeneij, F. and Laarman, G.J. (1993) Percutaneous Transradial Artery Approach for Coronary Stent Implantation. Catheterization and Cardiovascular Diagnosis, 30, 173-178. https://doi.org/10.1002/ccd.1810300220

[10] Tift Mann, J., Cubeddu, G., Schneider, J. and Arrowood, M. (1996) Right Radial Access for PTCA: A Prospective Study Demonstrates Reduced Complications and Hospital Charges. Journal of Invasive Cardiology, 8, 40D-44D.

[11] Hull, J.E., Kinsey, E.N. and Bishop, W.L. (2013) Mapping of the Snuffbox and Cubital Vessels for Percutaneous Arterial Venous Fistula (pAVF) in Dialysis Patients. The Journal of Vascular Access, 14, 245-251. https://doi.org/10.5301/jva.5000127

[12] McConnell, E.A. (1997) Performing Allen's Test. Nursing, 27, 26. https://doi.org/10.1097/00152193-199709000-00010

[13] Kiemeneij, F. (2000) Radial Hemostasis Devices: Alternatives for a Simple Pile of Gauze and Elastic Plasters? Journal of Invasive Cardiology, 12, 623-624.

[14] Stella, P.R., Kiameneij, F., Laarman, G.J., Odekerken, D., Slangboom, T. and Van 
der Wieken, R. (1997) Incidence and Outcome of Radial Artery Occlusion Following Transradial Artery Coronary Angioplasty. Catheterization and Cardiovascular Diagnosis, 40, 156-158.

https://doi.org/10.1002/(SICI)1097-0304(199702)40:2\%3C156::AID-CCD7\%3E3.0.C $\underline{\mathrm{O} ; 2-\mathrm{A}}$

[15] Kaledin, A.L., Kochanov, I.N., Podmetin, P.S., Seletsky, S.S. and Ardeev, V.N. (2017) Distal Radial Artery in Endovascular Interventions. Distal Radial Artery in Endovascular Interventions. (Unpublished)

[16] Gupta, S. and Nathan, S. (2015) Radial Artery Use and Reuse. Cardiac Interventions Today, 49-56. https://citoday.com/2015/06/radial-artery-use-and-reuse/

[17] Soydan, E. and Akın, M. (2018) Coronary Angiography Using the Left Distal Radial Approach-An Alternative Site to Conventional Radial Coronary Angiography. The Anatolian Journal of Cardiology, 19, 243-248.

https://doi.org/10.14744/AnatolJCardiol.2018.59932 